
\title{
$\begin{array}{ll}\text { Research Square } & \text { Preprints are preliminary reports that have not undergone peer review. } \\ \text { They should not be considered conclusive, used to inform clinical practice, } \\ \text { or referenced by the media as validated information. }\end{array}$ \\ Allee Effects Determine Pollinator Services at Local and Geographic Scales
}

Darío Sánchez-Castro ( $\sim$ Dario.sanchezcastro@unibas.ch )

University of Basel https://orcid.org/0000-0002-2552-1692

\section{Georg Armbruster}

University of Basel

Yvonne Willi

University of Basel

\section{Research Article}

Keywords: Abundance, Allee effect, attractiveness, flower size, latitudinal gradient, marginal population, small population size, visitation rate.

Posted Date: June 25th, 2021

DOI: https://doi.org/10.21203/rs.3.rs-591573/v1

License: (c) (i) This work is licensed under a Creative Commons Attribution 4.0 International License.

Read Full License 


\section{Abstract}

Climatic factors have attracted much attention in the study of species' distributions, while little is known about the role of biotic interactions. Here, we tested for variation in pollinator service across the distribution of a plant species, and evaluated the driving mechanisms. We monitored insect pollinators using time-lapse cameras in populations of North American Arabidopsis lyrata from the southern to the northern range limit. We spotted 67 pollinating insect taxa, indicating that this plant-pollinator network is a generalist system. Pollinator service increased with latitude. Higher pollinator visitation was correlated with the richness of other flowering plants and with plant census size, which was largest in northern populations. Furthermore, pollinator service reached a maximum at intermediate local flower density.

Synthesis: This study indicates that pollination service underlies Allee effects on a local and species' range scale, and that plant populations at range limits receive only marginal pollination service if they are small.

\section{Introduction}

Species' range limits, when not caused by dispersal limitation, should generally reflect the limits of the ecological niche. In many species, niches and ranges seem to be limited by climatic factors such as temperature and precipitation (Sexton et al., 2009). Species' distribution modelling (SDM) indicates that a handful of climate variables can often explain distribution limits rather well (e.g., Normand et al., 2009; Lee-Yaw et al., 2016). However, biotic interactions - possibly interacting with climate - have been considered less often in distribution modelling, and in the study of species' distribution limits more generally (Sexton et al., 2009). Neglect of biotic interactions is not justified because empirical studies show that they affect species persistence. Examples include interspecific competitors (Jankowski et al., 2010; Stanton-Geddes et al., 2012), parasites and pathogens (Briers, 2003; Coates et al., 2017), and herbivores (Galen, 1990; Benning et al., 2019). Mutualistic interactions are also known to affect species persistence, especially in plant-pollinator systems (Stone and Jenkins, 2008; Chalcoff et al., 2012; Moeller et al., 2012). Here we explored the mechanisms by which pollinators may help determine range limits of a plant.

Pollinator service is especially important for plant persistence as $80 \%$ of all temperate-zone flowering plant species rely on animals for pollination (Ollerton et al., 2011). At range edges, reduced pollinator service might constrain the abundance of plants that rely on animals as pollen vectors for reproduction (Gaston, 2009). Indeed, population persistence is commonly reduced at range edges. A meta-analysis of transplant experiments, mostly on plants, across and beyond range limits revealed that lifetime performance declined beyond the range in $83 \%$ of studies (Hargreaves et al., 2014). The decline could be caused by a change in climatic conditions beyond the edge (Lee-Yaw et al., 2016), but biotic interactions such as a lack of suitable pollinators could also contribute to range limits. Variation in pollinator service across the distribution of plant species can be related to climatic conditions that favour the activity of pollinators (Chalcoff et al., 2012; Moeller et al., 2012), but pollinator services could also vary due to 
attractiveness and pollinator preferences. For example, as climatic conditions deteriorate toward range limits - possibly together with habitat availability or habitat quality - population census size, local flower density, flower attractiveness or the richness of flowering plant species may decrease. Below we discuss in detail the mechanisms potentially reducing pollinator service and their relation with plant species' range limits.

One mechanism that may reduce pollinator service at a plant's range edge is based on the observation that across the distribution of a species, abundance tends to decline toward the edges, presumably because habitat suitability decreases toward range edges (Brown, 1984). The so-called 'abundant-center hypothesis' is broadly supported by a recent study documenting a decline of both the density of populations and the density of individuals within populations from the centre to the edges of species' distribution (Pironon et al., 2017). Lower regional and local densities of plants at range edges may also lower attractiveness to pollinators because pollinators commonly exhibit a preference for patches with a high density of flowering plants (reviewed by Ohashi and Yahara, 1999; Stone and Jenkins, 2008; Elliott and Irwin, 2009). This hypothesis describes an Allee effect (Courchamp et al., 1999), namely that pollinator service is lower in plant populations of small size and low density.

A second mechanism is reduced floral attractiveness at range edges. Animal-pollinated plants can sometimes enhance attractiveness to pollinators by producing more flowers per plant or larger flowers ( e.g., Klinkhamer and De Jong, 1990; Grindeland et al., 2005). However, investments in the floral display may be costly and hard to achieve if the environment is marginal and provides limited resources. Furthermore, plants of range edge populations often experience reduced individual performance from mutation accumulation due to genetic drift caused by past range expansion or long-term isolation (Willi et al., 2018; Willi and Van Buskirk, 2019; Perrier et al., 2020). Perrier et al. showed that a decline in performance of Arabidopsis lyrata at the range edge was caused by reduced flower production. Moreover, floral attractiveness may be lower at range edges because of a transition in the mating system from outcrossing to selfing (Morgan and Wilson, 2005; Moeller, 2006). Higher rates of self-compatibility and selfing have been noted in range-edge populations (e.g., Griffin and Willi, 2014), and this may be accompanied by changes in floral morphology such as a reduction in flower size (Darling et al., 2008; Dart et al., 2012). Hence, reduced attractiveness of flowers due to ecological or genetic causes may be another reason why pollinator service is low at range edges.

A third possible mechanism is related to the richness of flowering plant species and the diversity of resources offered to pollinators. Previous studies have reported a positive relationship between the diversity and abundance of pollinators and the diversity of flower types among co-occurring plants (e.g. Biesmeijer et al., 2006; Lázaro and Totland, 2010). The richness and abundance of other flowering plants increase the diversity of resources available to pollinators and therefore attract a broader diversity of insect visitors. If conditions at the edge of a species' range become marginal for several plant species and the community is therefore less diverse, pollinator service may generally decline. 
Finally, a fourth mechanism for reduced pollinator service at a plant's range edge is that climatic conditions may be unsuitable for pollinator activity. As conditions are expected to become harsher toward the edges, guilds of pollinators that are to some extent specialized on a community of plants may also decline in abundance. It is well known that pollinator abundance and metabolic activity are highly affected by temperature (Herrera, 1990; Hillyer and Silman, 2010; Rader et al., 2012; Knop et al., 2018). It is reasonable to propose that an environmental gradient that limits plant populations may have similar consequences for the pollinator assembly (e.g., Battisti et al., 2006).

In this study, we tested whether pollinator service decreased toward the range edges of a plant species (research question I) and explored the mechanisms at play (research question II). Our study organism was the short-lived perennial Arabidopsis lyrata subsp. lyrata in North America, which has been the subject of ongoing research focusing on the ecological and evolutionary causes of distribution limits (Lee-Yaw et al., 2018; Willi et al., 2018, 2020; Perrier et al., 2020; Sánchez-Castro et al., 2021 unpublished data). We assessed daily visitation of flowers by pollinators in 13 populations across a latitudinal gradient of $1100 \mathrm{~km}$ in the eastern United States, including replicate populations at the southern limit, centre of the range, and northern range limit. We quantified and identified pollinators using time-lapse cameras in each population, and tested the four mechanisms by relating pollinator data to population and site characteristics.

\section{Material And Methods}

\section{Study organism}

Arabidopsis lyrata comprises two subspecies with a circumpolar arctic-alpine distribution: A. lyrata subsp. petraea of central and northern Eurasia, and A. lyrata subsp. lyrata of central and eastern North America (Schmickl et al., 2010). The North American subspecies (hereafter abbreviated A. lyrata) has a well-defined distribution consisting of mainly two spatially separated ancestral genetic clusters in the US and Canada, from North Carolina to the state of New York in the east, and from Missouri to south-western Ontario in the Midwest (Willi and Määttänen, 2010; Willi et al., 2018). Populations normally occur on sand dunes and rocky outcrops, although they can also occur on sandy or rocky riverbanks and shorelines. In the Appalachians, plants grow on poor soils of coniferous leaf litter and moss on top of the bedrock, and under evergreen trees dominated by Virginia pine (Pinus virginiana) and Eastern Red Cedar (Juniperus virginiana). For this study, a total of 13 populations were monitored on a latitudinal gradient of $1100 \mathrm{~km}$ from North Carolina to upstate New York (Fig. 1A, Table S1).

A. lyrata is mostly outcrossing and insect-pollinated. However, some populations at the range edges are self-compatible and predominantly selfing (Griffin and Willi, 2014). Plants produce basal rosettes with inflorescences emerging throughout the flowering period (Fig. 1B), which takes place from mid-April to mid-June in eastern populations. Both the number of inflorescences and flowers per inflorescence vary considerably among populations and with the age of the plant. Flowers have white petals and nectar discs at the base of the anthers, and they emit volatiles to attract pollinators (Peer and Murphy, 2003). In 
A. lyrata subsp. petraea, volatiles are emitted from the petals between about 10:00 and 18:00, with a peak around midday (Abel et al., 2009). In one population on Isle Royale, Michigan, the dominant pollinators of A. lyrata are syrphid flies (Edwards et al., 2019)

\section{Pollination records}

Personal observations of pollinators in the field can lead to misinterpretation due to short observation periods (Rafferty and Ives, 2011; Hargreaves et al., 2015), the effect of the observer on insect behaviour (Peckham and Peckham, 1905), and the challenge of identifying live insects. As an alternative, we recorded pollinators using time-lapse cameras (TLC 200 Pro HDR, Brinno, Taipei City, Taiwan; Fig. 1C; Edwards et al., 2015). Time-lapse cameras take images at short intervals, capturing complete records over the entire day and allowing several patches in the same habitat to be monitored simultaneously. The cameras provide enough precision to identify and quantify flower visitors independently of the flower morphology or insect group (Edwards et al., 2015). In each population of A. lyrata, 10-12 cameras recorded separate flower patches for three 12-hour days, recording images at 3-sec intervals from 8 am to $8 \mathrm{pm}$ (see Table S1 for detailed observation period and patches recorded). The 3-sec interval has been shown to detect $90 \%$ of all visits (Edwards et al., 2015). As the abundance of insect visitors is highly affected by temperature, wind, and precipitation (Cruden, 1972; Roubik, 1989), observations were carried out only when the weather was sunny and the sky was clear. Monitoring was performed during the period of full bloom, from mid-April in the south to early June in the north, in two consecutive years (2018 and 2019). Two populations were monitored in both years.

Videos were examined with the Quick Time Player program (Apple, California, USA). Visits were considered only if there was direct contact of the insect with the pistil or stamens of the flower. We identified insects to the lowest taxonomic unit given the quality of the images, using Kits et al., (2008), Miranda et al., (2013), and Skevington et al., (2019) as identification keys. If the image was blurry and the pollinator unrecognizable, the taxon was categorized as "unidentifiable". Therefore, not all visits were identified to the same taxonomic depth. Some groups - especially in the Hymenoptera - were split into categories based on characters such as morphology, size, and colour pattern. We discarded from the analysis members of the Formicidae (ants) because their contribution to pollination is minimal (Junker et al., 2007). Curculionidae (weevils) were observed in one of the patches of a southern population, but not considered because it was difficult to see them. The genus Meligethes (Coleoptera) was considered to be a flower herbivore rather than a pollinator, so infested flowers were discarded from the analysis. For each patch and day, only mature and fully opened flowers in the video frame were considered.

Pollinator service was summarized with the following variables. Visitation rate was the total number of insect-flower interactions detected per day (abundance) divided by the total number of open flowers visible in the video frame. Pollination rate was the number of flowers visited at least once during the day divided by the total number of flowers in the video frame. Pollinator richness was the total number of different taxa/morphotypes observed. We also calculated Shannon (1948) biodiversity index based on pollinator abundance and richness at the level of camera and day. The complete sample size was: 13 
populations $\times 1-2$ years of recording per population $\times 10-12$ cameras per population and year $\times 2-4$ days of recording per camera $=382$ patches and days.

\section{Population and site characteristics}

We quantified several characteristics of populations and patches related to the hypothesized mechanisms by which pollinator service declines toward range limits. Plant census size was calculated by multiplying the area covered with $A$. lyrata by the average density of flowering plants. The area of occurrence was assessed by carefully screening for the presence and absence of the species. Local plant density was estimated at each patch where a camera was set up, as the total number of flowering plants per $\mathrm{m}^{2}$. Local flower density was the total number of open $A$. lyrata flowers per $\mathrm{m}^{2}$ at each patch. We assessed flower size on one flower from each of 40 randomly chosen, mature plants in each population, during mid-day when flowers were fully open. Flower size was the length of the ovary multiplied by the maximal width of the corolla. Finally, flowering plant species richness was the total number of flowering plant species co-occurring temporally and spatially with A. lyrata. To assess the effect of temperature, two data loggers (DS1922L, Maxim iButton, CA, USA) collected air temperature hourly at each population while cameras were recording. In summary, plant census size, flower size, plant species richness, and daily mean temperature were estimated on the level of the population and year, while local flower density was estimated on the level of the patch monitored within the population and year.

\section{Statistical analysis}

Daily visitation rate and pollination rate were the dependent variables. To test whether pollinator service declined from the centre of the distribution toward the edge (research question I), we analysed generalised linear mixed-effects model with restricted maximum likelihood, with the R packages Ime4 (Bates et al., 2015) and ImerTest (Kuznetsova et al., 2017) in R (R Core Team 2019). Fixed effects were explored for their relevance by model selection, based on AIC: latitude only (1), latitude and its square term (2), latitude and elevation (3) and latitude, its square term and elevation (4). All covariates were mean-centered (before taking the square). Random effects were camera nested within population and year, and population. Secondary dependent variables were pollinator richness and Shannon diversity index. Mechanistic variables were also tested for a relationship with latitude, its square term and elevation by model selection. These included population census size ( $\log _{10}$-transformed), local flower density $\left(\log _{10}\right.$-transformed), flower size, plant species richness, and daily mean temperature. Random effects were adjusted depending on levels of replication.

The mechanistic hypotheses about pollination service were addressed by testing the effects of $\log _{10^{-}}$ transformed population census size, $\log _{10}$-transformed local flower density, the square of logtransformed local flower density, flower size, plant species richness, and daily mean temperature on dependent variables of daily visitation rate and pollination rate (research question II). Fixed effects were mean-centered (before squaring). Random effects were camera within population and year, and heterogeneity in slopes of local flower density, squared local flower density, and mean temperature against population. 


\section{Results}

The total observation period for all populations, cameras and days was 4522 hours. During this recording time, 7310 flowers were monitored, and 17508 insects visited A. lyrata flowers. Visitors fell into 67 morphotypes, and $88 \%$ were identified to the taxonomic level of order (see Table S4 for the full list). About $49 \%$ of insects were Hymenoptera of the Apocrita group, followed by $48 \%$ Diptera (Table S2). Lepidoptera represented $3.2 \%$ of the visits and Coleoptera $0.1 \%$. The fraction of each insect order varied among populations, but there was no trend with latitude (Fig. 2A). Within the Diptera, Syrphidae and Bombyliidae were the most frequent visitors ( $46 \%$ and $32 \%$, respectively), followed by Muscoidea and Empididae (Fig 2B; Table S3). While southern A. Iyrata populations were visited more often by bombyliids; centre and northern populations were visited more frequently by syrphids (Fig 2B). Some taxa were observed in more than one population, particularly the hoverfly Toxomerus marginatus, which was a common visitor in all populations. Although several other insects occurred across the entire latitudinal gradient, there were also unique pollinators in each population. Some of the pollinator service variables were correlated (Fig. S1A): visitation rate and pollination rate $(r=0.51)$ and richness and diversity $(r=0.93)$.

The mechanistic variables hypothesized to be associated with pollinator service varied greatly. Population census size ranged from 600 to 378000 plants, and local flower density varied from 23 to 255 per $\mathrm{m}^{2}$ (Tables S5, S6). Flower size was largest in a self-compatible population in Virginia (VA2, see Table S6). The richness of flowering plant species ranged from 0 to 7 species (Tables S5, S7). Several of the mechanistic factors were significantly correlated (Fig. S1B).

\section{Does pollinator service decline from the centre toward range edges?}

Model selection for pollinator service and mechanistic variables indicated that the model with latitude alone was best supported by the data (Tables 1, S8). An exception was plant species richness, for which the model with latitude and its square term received the highest support.

Both visitation rate and pollination rate were positively correlated with latitude, with fewer pollinator interactions in southern populations (Fig. 3). Southern populations such as NC2 and VA2 received less than one visit per day, on average, and $60 \%$ of flowers were visited (Table S9). Meanwhile, in centre and northern populations such as WV1 and NY4, 3-5 pollinators per day were observed and over $80 \%$ of flowers were visited. Of the five mechanistic environmental variables, only population census size was associated (positively) with latitude (Fig. 3B).

\section{What are the mechanisms for reduced pollinator service?}

To address research question II, we tested for an association between pollinator service and potential mechanistic variables independent of the range position (Table 2). Visitation rate - as a trend - and pollination rate were positively related with population census size. The result is illustrated in Figure 4 on a map, with the large northern and centre populations having higher visitation and pollination rates. There was also an increase in visitation rate with the richness of flowering plant species (Fig. 3C). At the same 
time, high local flower density was associated with a lower visitation and pollination rate, indicating that pollinators did not visit patches proportional to local flower density but under-visited dense patches. This pattern was indicated by a significant negative linear term of local flower density for visitation rate and a significant negative quadratic term of local flower density for pollination rate (Table 2, Fig. 3D). The quadratic term further implied that also at low patch density of flowers, the chance of a flower being visited on a day was proportionally lower. The shape of curves depicting the relationship between pollination rate and local flower density within patches differed among populations, together within the position along the gradient of local flower density (Fig. 3D).

Analyses on further variables such as pollinator richness and Shannon diversity index revealed some role of local flower density (Table 2). A higher local flower density was associated with a higher pollinator richness and Shannon diversity index. Furthermore, larger flowers attracted a more diverse community of pollinators; the pattern was significant for pollinator richness and a trend for Shannon diversity index.

\section{Discussion}

Studies on range limits and species' distribution models have focused mainly on abiotic factors to understand the edges of geographic distributions. Here we showed that biotic interactions can contribute to or at least stabilize range limits. Pollinator service in $A$. lyrata was significantly lower in the south, and this could help establish the southern range limit. The mechanistic analyses indicated that low population census size was important: there were fewer flowering $A$. lyrata plants in the south and small population size was related with low visitation rate (as a trend) and lower probability of visitation. We discuss these and other results in the context of species' range limits and pollination biology in general.

\section{Does pollinator service decline from the centre toward range edges?}

Ecological niche modelling using recent climate data has shown that range limits in the south and north reflect niche limits for $A$. Iyrata (Lee-Yaw et al., 2018). A similar conclusion was supported by a transplant experiment to sites beyond the species' range in the south and north - southern range limits, but apparently not northern limits, reflect niche limits, and the main causes of performance decline were climatic (Sánchez-Castro et al., 2021 unpublished data). The results found here indicate that pollinator services are also not favourable for $A$. lyrata populations at the southern range limit (Fig. 3). In southern populations, flowers had an approximately $60 \%$ chance of receiving no visiting pollinators each day compared with $20 \%$ in northern populations (Fig. 3B). To evaluate the likely biological impact of this result, several factors should be considered. On the one hand, flowers are generally receptive to pollinators for two days, which increases the chance of being visited at least once by a pollinator. On the other hand, our field observations were done only during optimal conditions, when the weather was ideal for insect pollinators. Therefore, we think that across an entire blooming season many flowers in small southern populations may suffer from reduced insect visitation. Even if pollinators are not a primary 
source causing range limits, chronically low pollinator service may nevertheless contribute to reduced reproduction and small population size (Groom, 1998). In contrast to the south, northern range-edge populations did not receive reduced pollinator service. These results, in combination with the transplant experiment described earlier, suggest that northern edge populations are limited by neither climate nor a lack of pollinator service.

Previous studies have indicated that pollinators may enforce range limits. For example, populations of Witheringia solanacea in Costa Rica had greater visitation and fruit set in a lower montane site than at the upper elevational limit (Stone and Jenkins, 2008). Similar results were found for Embothrium coccineum in northwestern Patagonia, where lower pollinator service occurred in populations at the eastern range limit and climatic variables such as precipitation were not more important than biotic interactions (Chalcoff et al., 2012). For Clarkia xantiana in the Sierra Nevada, the abundance and visitation rates of pollinators decreased and pollen limitation increased at the range limits compared to centre populations (Moeller et al., 2012). However, Hargreaves et al., (2015) found no evidence that pollination activity decreased at the upper range limit for Rhinanthus minor in the Rocky Mountains. These mixed results motivated our examination of mechanisms that may affect pollinator service and whether they vary across the latitudinal gradient.

\section{What are the mechanisms for reduced pollinator service?}

One of the four hypothesized mechanisms for reduced pollinator service at the southern edge of the distribution was supported. Southern A. lyrata populations were smaller, and small populations attracted fewer insect pollinators. The positive relationships among the three variables of latitudinal position, census size and pollination rate (Fig. 3B) offer a plausible mechanism by which Allee effects operate in plants. In a now classic study performed by Groom (1998), she showed in experimental populations of Clarkia concinna that flowers of small and isolated populations were visited less frequently by pollinators than those of large populations - based on pollen counts. As a consequence, plants in small and isolated populations had a lower seed set and might therefore be more limited in spatial spread.

Our study found also evidence for an Allee effect independent of range position, on the scale of the local patch within populations. The relationship between pollinator visitation rate per flower and the density of flowers in the patch was hump-shaped, with low visitation rates at the lowest and highest flower densities (Fig. 4D). In other words, there was positive density dependence in visitation rate at low densities and negative density dependence at high densities. The relationship was similar across all populations, although the position of maximum visitation rate was shifted slightly downward along the gradient of local flower density. For average pollination, only negative density dependence was upheld. Previous studies have found mixed evidence for density dependence. While some studies revealed positive density dependence (Kunin, 1993; Delmas et al., 2016; Nielsen and Ims, 2000), there were also some showing a negative correlation (Hendrickson et al., 2018; Grindeland et al., 2005;) or no relationship (Kirchner et al., 2005). Our study confirmed that there was considerable variation in density dependence for pollination among the populations, but that the pattern of an Allee effect was nevertheless applicable across the species. 
Finally, and also independent of range position, we found that average visitation rate of flowers increased with plant species richness. This result is well in line with research that showed that the diversity of floral resources increases the visitation rate (Ghazoul, 2006; Hegland and Boeke, 2006) and that it attracts a greater number of pollinator species (Lázaro and Totland, 2010).

\section{Pollination biology of A. lyrata}

A recent study on one A. lyrata population in Isle Royale pointed to Syrphids as main flower visitors, in particular the genus Toxomerus (Edwards et al., 2019). By extending the geographical range of the study, we found that both Hymenoptera and Diptera were equally important as main pollinators, while Lepidoptera represented a small proportion of the visits (Fig. 2A). Within the Diptera, hoverflies were the most frequent family in the centre and northern populations, supporting the previous results of Edwards et al. (2019), while Bombyliidae predominated at lower latitudes (Fig. 2B). Even though we found some common pollinators in all populations such as Toxomerus, most flowers were visited by multiple insect taxa. Findings support that many pollinators of the temperate zone are opportunists with labile preferences of pollen and nectar. Results also demonstrate that the pollination network is a generalist system that provides ecological flexibility in terms of reproduction for the plant, and a diversity of food resources for the pollinators (Waser et al., 1996; Fenster et al., 2004).

Furthermore, our research provided some noteworthy results on the distribution of pollinator diversity. First, we did not find that pollinator diversity was increased at southern compared to northern latitudes, as e.g., suggested by Schemske et al. (2009). However, despite plant census size of $A$. lyrata being lower in the south, and visitation and pollination rates declining accordingly, pollinator diversity was not lower. Pollinator diversity was higher in populations that had larger flowers. Finally, pollinator diversity was also higher on patches with a higher density of flowers, which to some extent could be a sampling effect.

\section{Conclusion}

Pollinator service varied across the distribution of $A$. lyrata. Southern range edge populations had lower visitation rates by pollinators, and this was linked with their smaller census size. The result points to limited pollination service as an important stabilizer of range limits. Apart from this Allee effect on the level of the population, we also found evidence for an Allee effect on the level of local patches within populations. In patches of low density, the chance of a flower being visited at least once a day was lower compared to flowers of mid-density patches; at higher densities, density dependence changed to negative. The two levels of positive density dependence under small size or density support a very important role of Allee effects in pollination.

\section{Declarations}

\section{Acknowledgements}


This research was supported by the Swiss National Science Foundation (31003A_166322 to Y.W.). We would like to thank Joan Edwards (Williams College, Williamstown, MA) for inspiration and inputs to this project. For support in fieldwork and monitoring permits, we thank: Randy Carter, Blowing Rock Park, Maryland Department of Natural Resources, Clark Reservation State Park, Cornell University, Palisades Interstate Park Commission, Nature Conservancy of Maryland, Virginia Department of Forestry, and New York State Office of Parks. For assistance with pollinators counts, we thank Susanna Riedl and Jacob Dench, and Josh Van Buskirk for commenting on the manuscript.

Author contributions: DSC designed the study, performed the field-work and analyzed the data, with inputs by GA and YW. GA identified the insect taxa. DSC wrote the first draft of the manuscript, and GA and $\mathrm{YW}$ contributed to revisions. The authors declare no conflicts of interest

Data accessibility statement: All data will be stored in Dryad if accepted

\section{References}

1. Abel C, Clauss M, Schaub A, Gershenzon J, Tholl D (2009) Floral and insect-induced volatile formation in Arabidopsis lyrata ssp. petraea, a perennial, outcrossing relative of $A$. thaliana. Planta 230:1-11. https://doi.org/10.1007/s00425-009-0921-7

2. Ashman T-L, Knight TM, Steets JA, Amarasekare P, Burd M, Campbell DR et al (2004) Pollen limitation of plant reproduction: ecological and evolutionary causes and consequences. Ecology 85:2408-2421. http://dx.doi.org/10.1890/03-8024

3. Bates D, Mächler M, Bolker B, Walker S (2015) Fitting linear mixed-effects models using Ime4. J Stat Softw 67:1-48. https://doi.org/10.18637/jss.v067.i01

4. Battisti A, Stastny M, Buffo E, Larsson S (2006) A rapid altitudinal range expansion in the pine processionary moth produced by the 2003 climatic anomaly. Glob Change Biol 12:662-671. https://doi.org/10.1111/j.1365-2486.2006.01124.x

5. Benning JW, Moeller DA (2019) Maladaptation beyond a geographic range limit driven by antagonistic and mutualistic biotic interactions across an abiotic gradient. Evolution 73:2044-2059. https://doi.org/10.1111/evo.13836

6. Biesmeijer JC, Roberts SPM, Reemer M, Ohlemüller R, Edwards M, Peeters T et al (2006) Parallel declines in pollinators and insect-pollinated plants in Britain and the Netherlands. Science 313:351354. https://doi.org/10.1126/science. 1127863

7. Briers RA (2003) Range limits and parasite prevalence in a freshwater snail. Proceedings of the Royal Society: Biological Science, 270, S178-S180. https://doi.org/10.1098/rsbl.2003.0046

8. Brown JH (1984) On the relationship between abundance and distribution of species. Am Nat 124:255-279. https://doi.org/10.1086/284267

9. Chalcoff VR, Aizen MA, Ezcurra C (2012) Erosion of a pollination mutualism along an environmental gradient in a south Andean treelet, Embothrium coccineum (Proteaceae). Oikos 121:471-480. 
https://doi.org/10.1111/j.1600-0706.2011.19663.x

10. Coates A, Barnett LK, Hoskin C, Phillips BL (2017) Living on the edge: parasite prevalence changes dramatically across a range edge in an invasive gecko. Am Nat 189:178-183. https://doi.org/10.1086/689820

11. Courchamp F, Clutton-Brock T, Grenfell B (1999) Inverse density dependence and the Allee effect. Trend in Ecology Evolution 14:405-410. https://doi.org/10.1016/S0169-5347(99)01683-3

12. Cruden RW (1972) Pollinators in high-elevation ecosystems: relative effectiveness of birds and bees. Science 176:1439-1440. https://doi.org/10.1126/science.176.4042.1439

13. Darling E, Samis KE, Eckert CG (2008) Increased seed dispersal potential towards geographic range limits in a Pacific coast dune plant. New Phytol 178:424-435. https://doi.org/10.1111/j.14698137.2007.02349.x

14. Dart SR, Samis KE, Austen E, Eckert CG (2012) Broad geographic covariation between floral traits and the mating system in Camissoniopsis cheiranthifolia (Onagraceae): multiple stable mixed mating systems across the species' range? Ann Bot 109:599-611. https://doi.org/10.1093/aob/mcr266

15. Delmas CEL, Fort TLC, Escaravage N, Pornon A (2016) Pollen transfer in fragmented plant populations: insight from the pollen loads of pollinators and stigmas in a mass-flowering species. Ecology Evolution 6:5663-5673. https://doi.org/10.1002/ece3.2280

16. Edwards J, Griffin AJ, Knoedler MR (2019) Simultaneous recordings of insect visitors to flowers show spatial and temporal heterogeneity. Annals of the Entomology Society of America 117:93-98. https://doi.org/10.1093/aesa/say044

17. Edwards J, Smith GP and. McEntee MHF (2015) Long-term time-lapse video provides near complete records of floral visitation. Journal of Pollination Ecology, 16, 91-100. http://dx.doi.org/10.26786/1920-7603\%282015\%2916

18. Elliott SE, Irwin RE (2009) Effects of flowering plant density on pollinator visitation, pollen receipt, and seed production in Delphinium barbeyi (Ranunculaceae). The American Journal of Botany 96:912-919. https://doi.org/10.3732/ajb.0800260

19. Fenster CB, Armbruster WS, Wilson P, Dudash MR, Thomson JD (2004) Pollination syndromes and floral specialization. Annu Rev Ecol Evol Syst 35:375-403. https://doi.org/10.1146/annurev.ecolsys.34.011802.132347

20. Galen C (1990) Limits to the distributions of alpine tundra plants: herbivores and the alpine skypilot, Polemonium viscosum. Oikos 59:355-358

21. Gaston KJ (2009) Geographic range limits: achieving synthesis. Proceedings of the Royal Society: Biological Science, 276, 1395-1406. https://doi.org/10.1098/rspb.2008.1480

22. Ghazoul J (2006) Floral diversity and the facilitation of pollination. J Ecol 94:295-304. https://doi.org/10.1111/j.1365-2745.2006.01098.x

23. Griffin PC, Willi Y (2014) Evolutionary shifts to self-fertilisation restricted to geographic range margins in North American Arabidopsis lyrata. Ecology letters 17:484-490. https://doi.org/10.1111/ele.12248 
24. Grindeland JM, Sletvold N, Ims RA (2005) Effects of floral display size and plant density on pollinator visitation rate in a natural population of Digitalis purpurea. Funct Ecol 19:383-390. https://doi.org/10.1111/j.1365-2435.2005.00988.x

25. Groom MJ (1998) Allee effects limit population viability of an annual plant. Am Nat 151:487-496. https://doi.org/10.1086/286135

26. Hargreaves AL, Samis KE, Eckert CG (2014) Are species' range limits simply niche limits writ large ? A review of transplant experiments beyond the range. Am Nat 183:157-173. https://doi.org/10.1086/674525

27. Hargreaves AL, Weiner JL, Eckert CG (2015) High-elevation range limit of an annual herb is neither caused nor reinforced by declining pollinator service. J Ecol 103:572-584. https://doi.org/10.1111/1365-2745.12377

28. Hegland SJ, Boeke L (2006) Relationships between the density and diversity of floral resources and flower visitor activity in a temperate grassland community. Ecol Entomol 31:532-538

29. Hendrickson EC, Thompson PG, Cruzan MB (2018) Density dependent pollination and germination in the patchy vernal pool species Lasthenia californica. International Journal of Plant Science 179:583-591. https://doi.org/10.1111/j.1365-2311.2006.00812.x

30. Herrera CM (1990) Daily patterns of pollinator activity, differential pollinating effectiveness, and floral resource availability, in a summer-flowering Mediterranean shrub. Oikos 58:277-288

31. Hillyer R, Silman MR (2010) Changes in species interactions across a $2.5 \mathrm{~km}$ elevation gradient: effects on plant migration in response to climate change. Glob Change Biol 16:3202-3214. https://doi.org/10.1111/j.1365-2486.2010.02268.x

32. Jankowski JE, Robinson SK, Levey DJ (2010) Squeezed at the top: interspecific aggression may constrain elevational ranges in tropical birds. Ecology 91:1877-1884. https://doi.org/10.1890/092063.1

33. Junker R, Chung AYC, Blüthgen N (2007) Interaction between flowers, ants and pollinators: additional evidence for floral repellence against ants. Ecol Res 22:665-670. https://doi.org/10.1007/s11284006-0306-3

34. Kirchner F, Luijten SH, Imbert E, Riba M, Mayol, González-Martinez SC et al (2005) Effects of local density on insect visitation and fertilization success in the narrow-endemic Centaurea corymbosa (Asteraceae). Oikos 111:130-142. https://doi.org/10.1111/j.0030-1299.2005.14022.x

35. Kits JH, Marshall SA, Evenhuis NL (2008) The bee flies (Diptera: Bombyliidae) of Ontario, with a key to the species of eastern Canada. C.J.A.I., 6

36. Klinkhamer PGL, De Jong TJ (1990) Effects of plant size, plant density and sex differential nectar reward on pollinator visitation in the protandrous Echium Vulgare (Boraginaceae). Oikos 57:399405. https://doi.org/10.2307/3565970

37. Knop E, Gerpe C, Ryser R, Hofmann F, Menz MHM, Trösch S et al (2018) Rush hours in flower visitors over a day-night cycle. Insect Conservation Diversity 11:267-275.

https://doi.org/10.1111/icad.12277

Page $13 / 18$ 
38. Kunin WE (1997) Population size and density effects in pollination: pollinator foraging and plant reproductive success in experimental arrays of Brassica kaber. J Ecol 85:225-234. https://doi.org/10.2307/2960653

39. Kuznetsova, A., Brockhoff, P.B. and Christensen, R.H.B. (2017). ImerTest package: tests in linear mixed effects models. Journal of Statistical Software, 82, 1-26. https://doi.org/10.18637/jss.v082.i13

40. Lázaro A, Totland O (2010) Local floral composition and the behaviour of pollinators: attraction to and foraging within experimental patches. Ecol Entomol 35:652-661. https://doi.org/10.1111/j.1365-2311.2010.01223.x

41. Lee-Yaw JA, Fracassetti M, Willi Y (2018) Environmental marginality and geographic range limits: a case study with Arabidopsis lyrata ssp. lyrata. Ecography 41:622-634. https://doi.org/10.1111/ecog.02869

42. Lee-Yaw JA, Kharouba HM, Bontrager M, Mahony C, Csergő AM, Noreen AME et al (2016) A synthesis of transplant experiments and ecological niche models suggests that range limits are often niche limits. Ecology letters 19:710-722. https://doi.org/10.1111/ele.12604

43. Miranda GFG, Young AD, Locke MM, Marshall SA, Skevington JH, Thompson FC (2013) Key to the genera of Nearctic Syrphidae. C.J.A.I., 23

44. Moeller DA (2006) Geographic structure of pollinator communities, reproductive assurance, and the evolution of self-pollination. Ecology 87:1510-1522. https://doi.org/10.1890/00129658(2006)87[1510:GSOPCR]2.0.C0;2

45. Moeller DA, Geber MA, Eckhart VM, Tiffin P (2012) Reduced pollinator service and elevated pollen limitation at the geographic range limit of an annual plant. Ecology 93:1036-1048. https://doi.org/10.1890/11-1462.1

46. Morgan MT, Wilson WG (2005) Self-fertilization and the escape from pollen limitation in variable pollination environments. Evolution 59:1143-1148

47. Nielsen A, Ims RA (2000) Bumblebee pollination of the sticky catchfly in a fragmented agricultural landscape. Ecoscience 7:157-165. https://doi.org/10.1080/11956860.2000.11682584

48. Normand S, Treier UA, Randin C, Vittoz P, Guisan A, Svenning JC (2009) Importance of abiotic stress as a range-limit determinant for European plants: insights from species responses to climatic gradients. Glob Ecol Biogeogr 18:437-449. https://doi.org/10.1111/j.1466-8238.2009.00451.x

49. Ohashi K, Yahara T (1999) How long to stay on, and how often to visit a flowering plant? - a model for foraging strategy when floral displays vary in size. Oikos 86:386-392

50. Ollerton J, Winfree R, Tarrant S (2011) How many flowering plants are pollinated by animals? Oikos 120:321-326. https://doi.org/10.1111/j.1600-0706.2010.18644.x

51. Peckham GW, Peckham EG (1905) Wasps: social and solitary. Constable and company, Westminster

52. Peer WA, Murphy AS (2003) Floral scent of Arabidopsis lyrata (Brassicaceae). Biochem Syst Ecol 31:1193-1195 
53. Perrier A, Sánchez-Castro D, Willi Y (2020) Expressed mutational load increases toward the edge of a species' geographic range. Evolution 74:1711-1723. https://doi.org/10.1111/evo.14042

54. Pironon S, Papuga G, Villellas J, Angert AL, García MB, Thompson JD (2017) Geographic variation in genetic and demographic performance: new insights from an old biogeographical paradigm. Biol Rev 92:1877-1909. https://doi.org/10.1111/brv.12313

55. R Core Team (2019) R: A Language and Environment for Statistical Computing. R Foundation for Statistical Computing, Vienna, Austria. URL: https://www.R-project.org/

56. Rader R, Howlett BG, Cunningham SA, Westcott DA, Edwards W (2012) Spatial and temporal variation in pollinator effectiveness: do unmanaged insects provide consistent pollination services to mass flowering crops? Journal of Applied Ecology 49:126-134. https://doi.org/10.1111/j.13652664.2011.02066.x

57. Rafferty NE, Ives AR (2011) Effects of experimental shifts in flowering phenology on plant-pollinator interactions. Ecology letters 14:69-74. https://doi.org/10.1111/j.1461-0248.2010.01557.x

58. Roubik DW (1989) Ecology and natural history of tropical bees. Cambridge University Press, Cambridge

59. Schemske DW, Mittelbach GG, Cornell HV, Sobel JM, Roy K (2009) Is there a latitudinal gradient in the importance of biotic interactions? Annu Rev Ecol Evol Syst 40:245-269.

https://doi.org/10.1146/annurev.ecolsys.39.110707.173430

60. Schmickl R, Jørgensen MH, Brysting AK, Koch MA (2010) The evolutionary history of the Arabidopsis lyrata complex: A hybrid in the amphi-Beringian area closes a large distribution gap and builds up a genetic barrier. BMC Evol Biol 10:1-18. https://doi.org/10.1186/1471-2148-10-98

61. Sexton JP, Mclntyre PJ, Angert AL, Rice KJ (2009) Evolution and ecology of species range limits. Annu Rev Ecol Evol Syst 40:415-436. https://doi.org/10.1146/annurev.ecolsys.110308.120317

62. Shannon CE (1948) A mathematical theory of communication. The bell systems technical journal 27:379-423

63. Skevington JH, Locke MM, Young AD, Moran K, Crins WJ, Marshall S (2019) Field guide to the flower flies of Northeastern North America. Princeton University Press

64. Stanton-Geddes J, Anderson CG (2011) Does a facultative mutualism limit species range expansion? Oecologia 167:149-155. https://doi.org/10.1007/s00442-011-1958-4

65. Stanton-Geddes J, Tiffin P, Shaw RG (2012) Role of climate and competitors in limiting fitness across range edges of an annual plant. Ecology 93:1604-1613. https://doi.org/10.1890/11-1701.1

66. Stone JL, Jenkins EG (2008) Pollinator abundance and pollen limitation of a Solanaceous shrub at premontane and lower montane sites. Biotropica 40:55-61. https://doi.org/10.1111/j.17447429.2007.00339.x

67. Waser NM, Chittka L, Price MV, Williams NM, Ollerton J (1996) Generalization in pollination systems, and why it matters. Ecology 77:1043-1060. https://doi.org/10.2307/2265575 
68. Willi Y, Fracassetti M, Bachmann O, Van Buskirk J (2020) Demographic processes linked to genetic diversity and positive selection across a species' range. Plant Communications 1:100111. https://doi.org/10.1016/j.xplc.2020.100111

69. Willi Y, Määttänen K (2010) Evolutionary dynamics of mating system shifts in Arabidopsis lyrata. J Evol Biol 23:2123-2131. https://doi.org/10.1111/j.1420-9101.2010.02073.x

70. Willi Y, Van Buskirk J (2019) A practical guide to the study of distribution limits. Am Nat 193:773785. https://doi.org/10.1086/703172

71. Willi Y, Fracassetti M, Zoller S, Van Buskirk J (2018) Accumulation of mutational load at the edges of a species range. Mol Biol Evol 35:781-791. https://doi.org/10.1093/molbev/msy057

\section{Tables}

Due to technical limitations, table 1-2 is only available as a download in the Supplemental Files section.

\section{Figures}

(A)

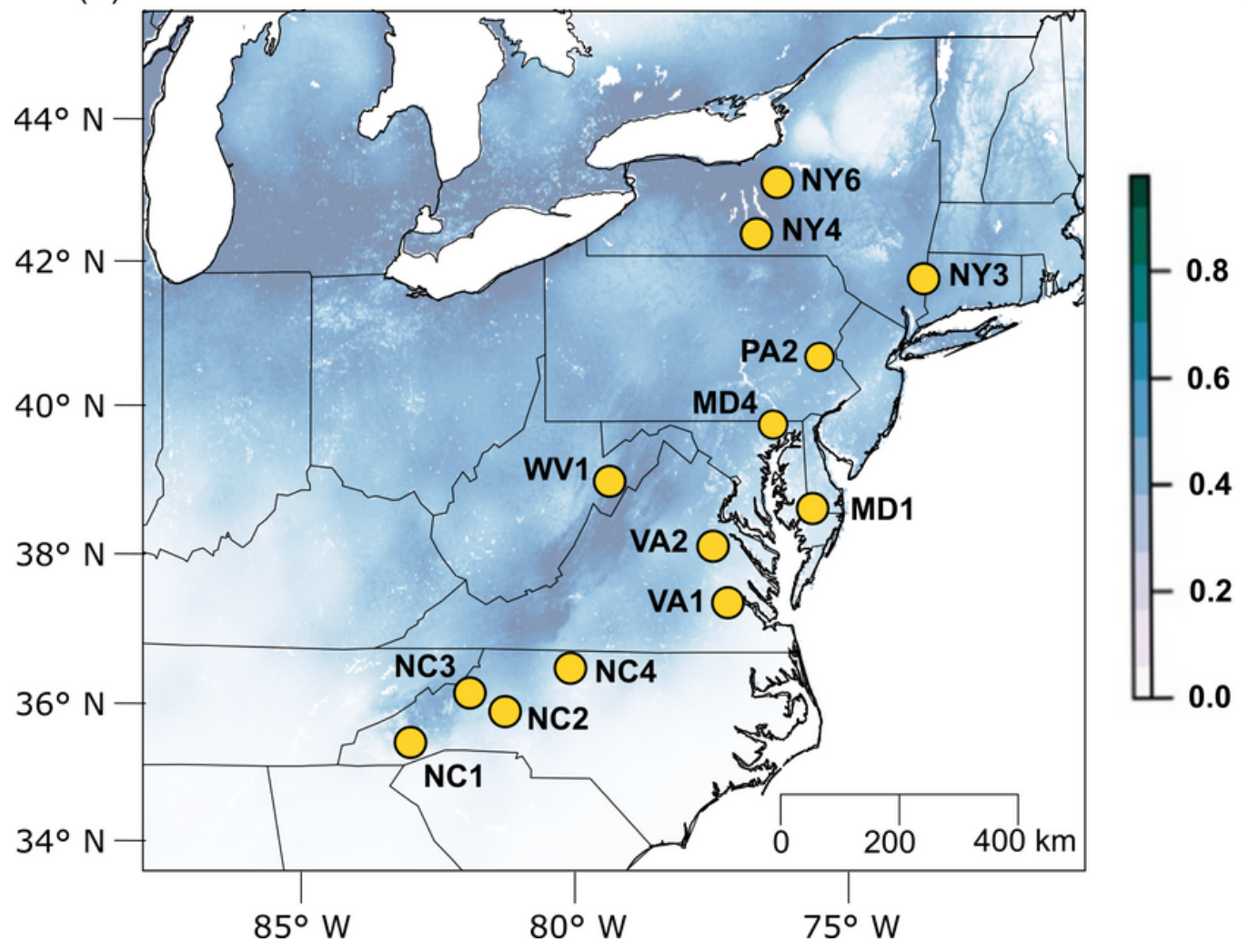

(B)

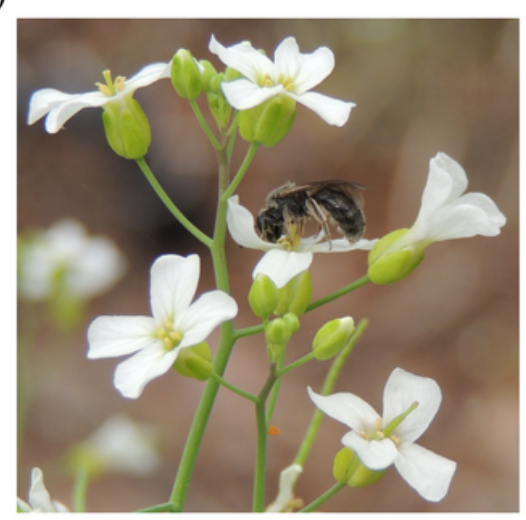

(C)

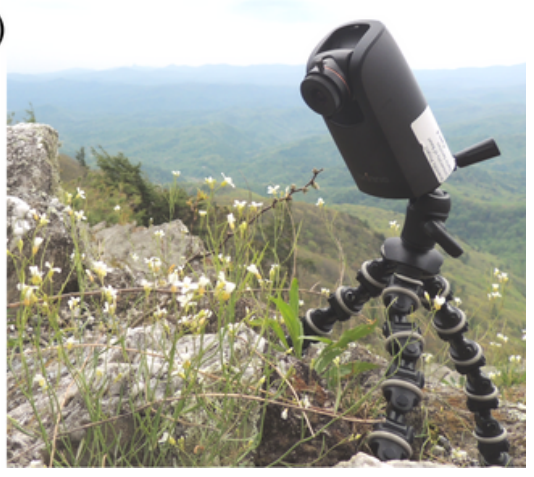

Figure 1

Locations of the 13 Arabidopsis lyrata populations studied for pollinator service in North America (A), an image of A. lyrata flowers with a wild bee visiting (B), and a time-lapse camera monitoring a patch of flowers in the field (C). Panel A shows populations indicated by dots accompanied by a three-digit abbreviation (Table S1, the two letters stand for the state in the US, and the number is the latitudinal 
position within the state as in Willi et al., 2018). Shades of blue indicate habitat suitability revealed by niche-modelling (Lee-Yaw et al., 2018).

(A)

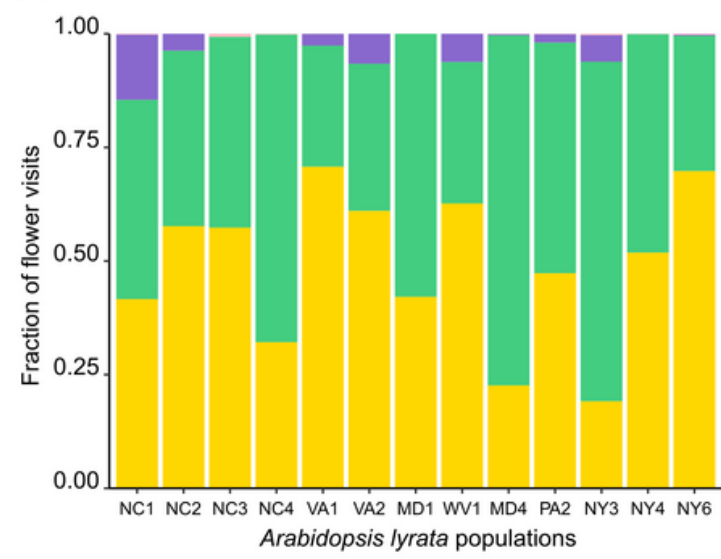

(B)

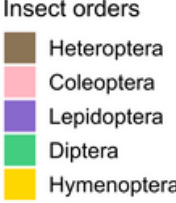

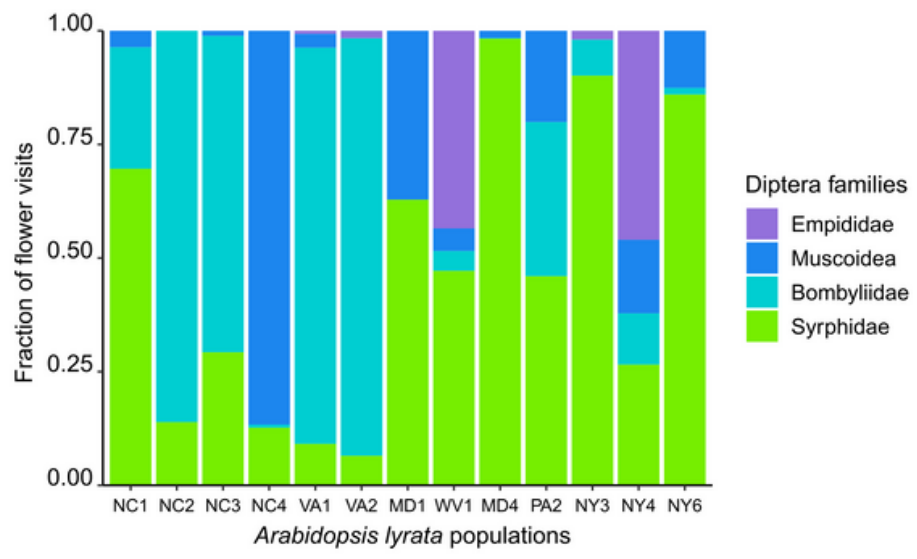

Figure 2

The taxonomic composition of insect orders (A) and Diptera families (B) that visited Arabidopsis lyrata flowers in the 13 populations, sorted from south (left in the x-axis) to north (right). For population abbreviations see Fig. 1.

(A)

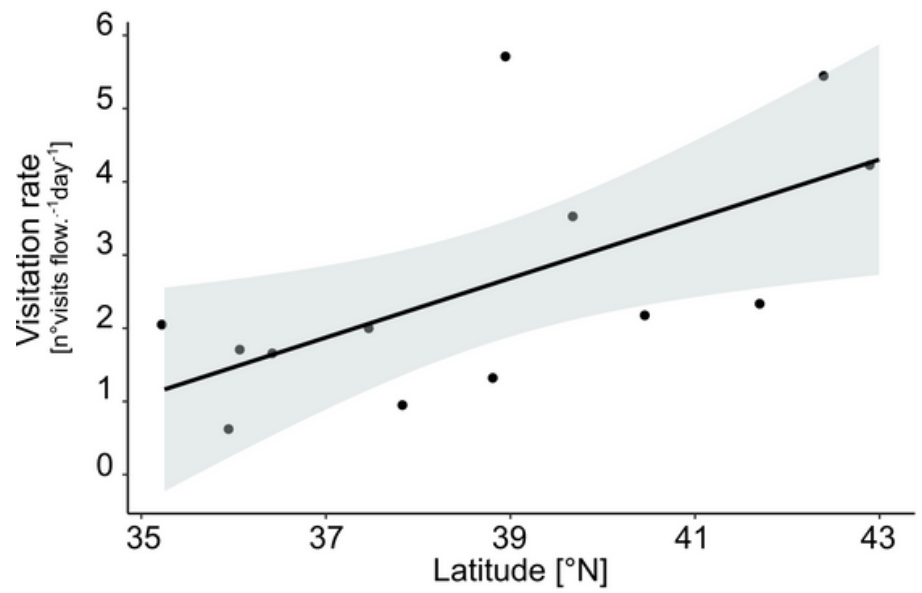

(C)

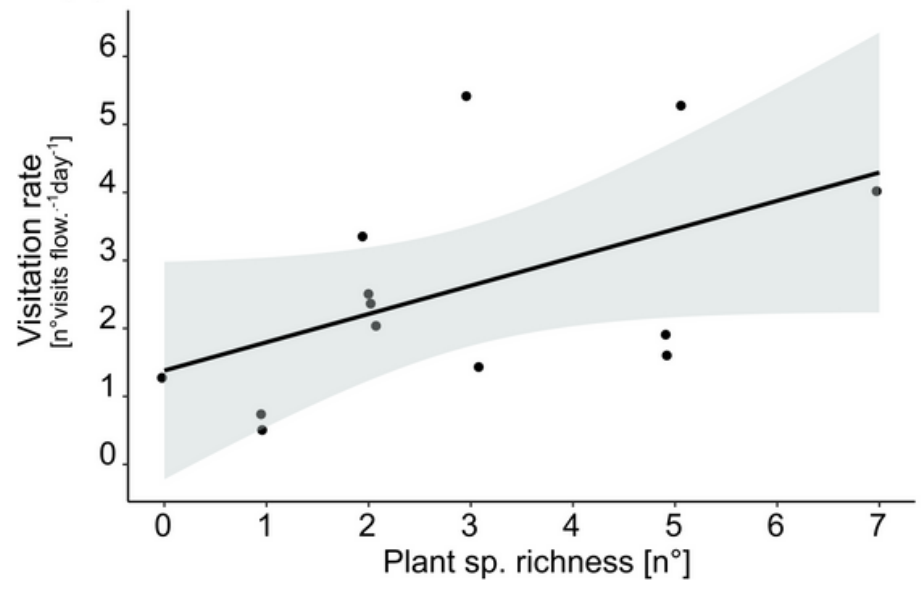

(B)

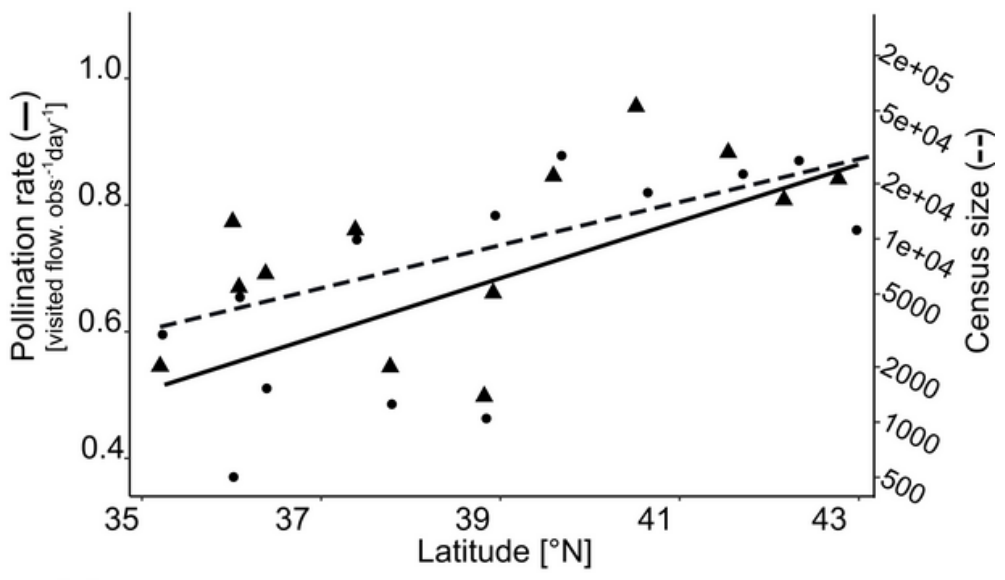

(D)

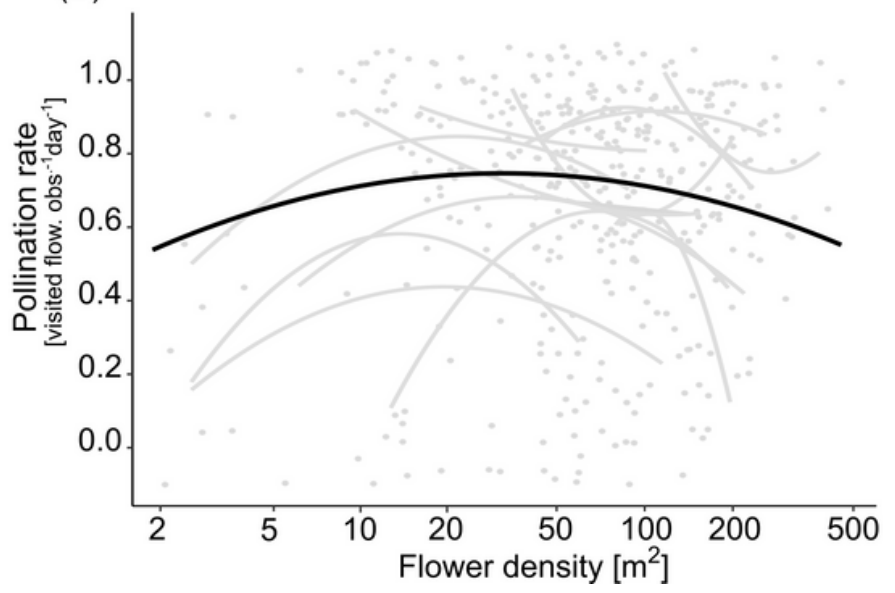

Figure 3 
Relationship between insect visitation rate per flower and day (left panels) or pollination rate per flower and day (right panels) and the latitudinal position (top), plant species richness (C) or local flower density (D) in Arabidopsis lyrata populations. In panels A-C, symbols represent population values; in D, symbols represent patch values. In $\mathrm{B}$, symbols are population mean pollination rate and triangles are population census size. The black lines are model-predicted relationships (dashed line for census size), with lower and upper $95 \%$ confidence interval (A, C). In D, curves represent quadratic relationships between pollination rate and log10-transformed local flower density overall (black) and for each population separately (grey). For statistics, see Tables 1 and 2.

(A)

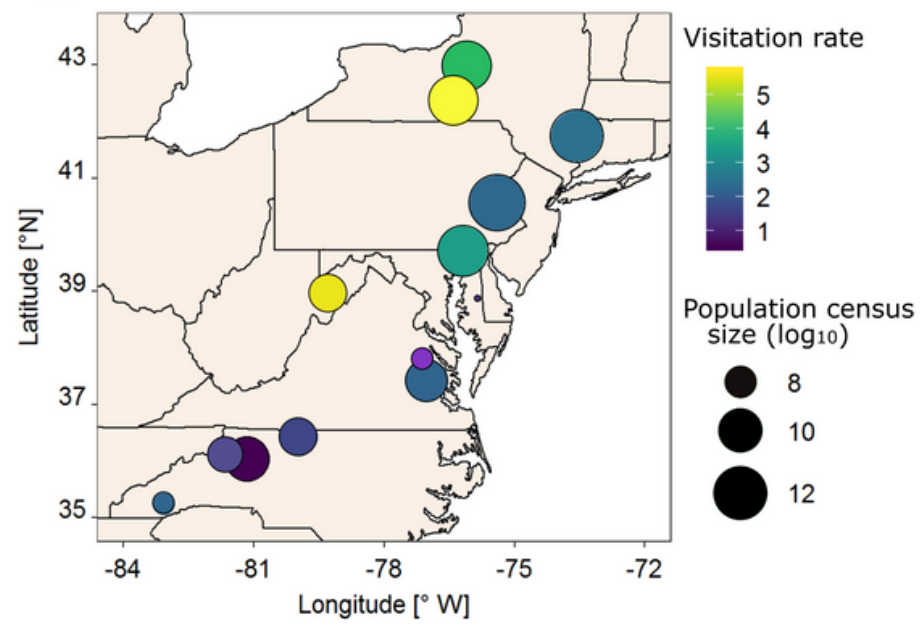

(B)

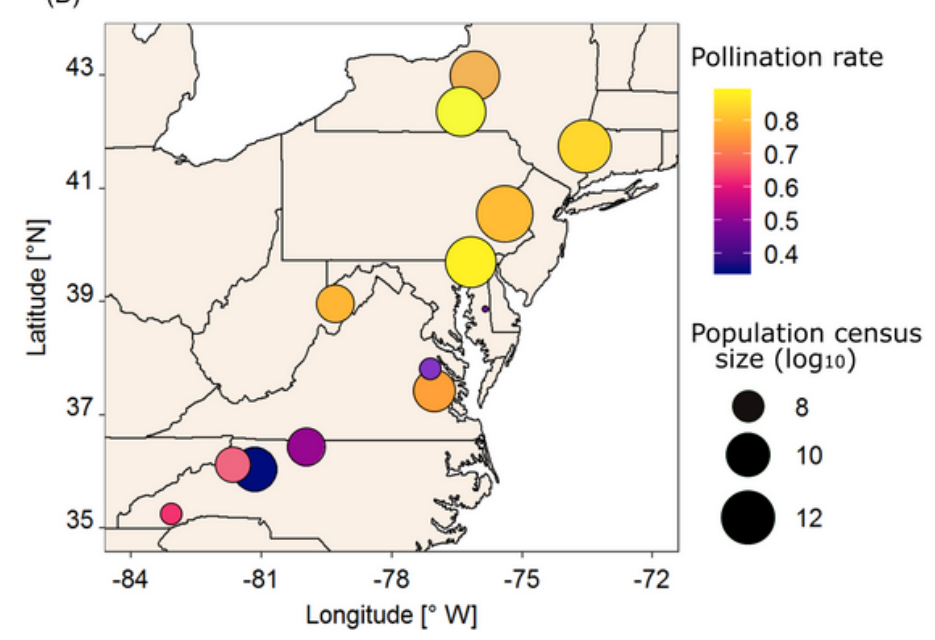

Figure 4

Maps illustrating relationships among visitation rate (A) and pollination rate (B), population census size, and geography in the 13 populations of Arabidopsis lyrata. The diameter of the symbol represents the census size and the colour indicates the population mean of visitation rate or pollination rate, respectively. Population means were based on temporal replicates, then cameras, and finally on year.

\section{Supplementary Files}

This is a list of supplementary files associated with this preprint. Click to download.

- Tables.pdf

- MS3pollservicesupplementary.docx 